\title{
THE RELATIONSHIP BETWEEN TRUCK ACCIDENTS AND GEOMETRIC DESIGN OF ROAD SECTIONS: POISSON VERSUS NEGATIVE BINOMIAL REGRESSIONS
}

\author{
Shaw-Pin Miaou \\ Center for Transportation Analysis, Energy Division \\ Oak Ridge National Laboratory \\ P.O.Box 2008, MS 6366, Building 5500A \\ Oak Ridge, TN 37831, USA \\ Phone: (615) 574-6933, Fax: (615) 574-3851
}

July 1993

\author{
Prepared by \\ OAK RIDGE NATIONAL LABORATORY \\ Oak Ridge, Tennessee 37831 \\ managed by \\ MARTIN MARIETTA ENERGY SYSTEMS, INC. \\ for the \\ U.S. Department of Energy \\ under \\ Contract No. DE-AC05-84OR21400
}

\section{CAUTION}

The submitted manuscript has been authored by a consactor of the U.S. Govemmens under consuact Na. DE-ACO5-84OR21400 Accordingty, the U.S. Govemment resains a nonesclusive, royaly-free licase to publish or reproduce the published form of this coneribution, or allow ochers to do so for U.S. Governmen puppases"

\section{DISCLAIMER}

This report was prepared as an account of work sponsored by an agency of the United States Government. Neither the United States Government nor any agency thereof, nor any of their employees, makes any warranty, express or implied, or assumes any legal liability or responsibility for the accuracy, completeness, or usefulness of any information, apparatus, product, or process disclosed, or represents that its use would not infringe privately owned rights. Reference herein to any specific commercial product, process, or service by trade name, trademark, manufacturer, or otherwise does not necessarily constitute or imply its endorsement, recommendation, or favoring by the United States Government or any agency thereof. The views and opinions of authors expressed herein do not necessarily state or reflect those of the United States Government or any agency thereof. 


\title{
THE REI ATIONSHIP BETWEEN TRUCK ACCIDENTS AND GEOMETRIC DESIGN OF ROAD SECTIONS: POISSON VERSUS NEGATIVE BINOMIAL REGRESSIONS
}

\author{
Shaw-Pin Miaou \\ Center for Transportation Analysis, Energy Division \\ Oak Ridge National Laboratory \\ P.O.Box 2008, MS 6366, Oak Ridge, TN 37831, USA \\ Phone: (615) 574-6933, Fax: (615) 574-3851
}

\begin{abstract}
This paper evaluates the performance of Poisson and negative binomial (NB) regression models in establishing the relationship between truck accidents and geometric design of road sections. Three types of models are considered: Poisson regression, zero-inflated Poisson (ZIP) regression, and NB regression. Maximum likelihood (ML) method is used to estimate the unknown parameters of these models. Two other feasible estimators for estimating the dispersion parameter in the NB regression model are also examined: a moment estimator and a regression-based estimator. These models and estimators are evaluated based on their (1) estimated regression parameters, (2) overall goodness-offit, (3) estimated relative frequency of truck accident involvements across road sections, (4) sensitivity to the inciusion of short road sections, and (5) estimated total number of truck accident involvements. Data from the Highway Safety Information System (HSIS) are employed to examine the performance of these models in developing such relationships. The evaluati- " results suggest that the NB regression model estimated using the moment and regression-based methods should be used with caution. Also, under the ML method, the estimated regression parameters from all three models are quite consistent and no particular model outperforms the other two models in terms of the estimated relative frequencies of truck accident involvements across road sections. It is recommended that the Poisson regression model be used as an initial model for developing the relationship. If the overdispersion of accident data is found to be moderate or high, both the NB and ZIP regression models could be explored. Overall, the ZIP regression model appears to be a serious candidate, model when data exhibit excess zeros due, e.g., to underreporting. However, the interpretation of the ZIP model can be difficult.
\end{abstract}

Key Words: Truck Accidents, Geometric Design, Poisson, Zero-Inflated Poisson, Negative Binomial. 


\title{
THE REI ATIONSHIP BETWEEN TRUCK ACCIDENTS AND GEOMETRIC DESIGN OF ROADWAY SECTIONS: POISSON VERSUS NEGATTVE BINOMIAL REGRESSION
}

\author{
Shaw-Pin Miaou \\ Center for Transportation Analysis, Energy Division \\ Oak Ridge National Laboratory \\ P.O.Box 2008, MS 6366, Oak Ridge, TN 37831, USA \\ Phone: (615) 574-6933, Fax: (615) 574-3851
}

\section{INTRODUCTION}

The relationship between vehicle accidents and geometric design of road sections, such as horizontal curvature, vertical grade, lane width, and shoulder width, have been studied using multiple linear regression models in numerous previous studies [Roy Jorgensen Associates, Inc., 1978; Zegeer et al., 1987; Okamoto and Koshi, 1989; Zegeer et al., 1990]. Because the occurrences of vehicle accidents are typically sporadic across the road network, in most vehicle accidents-geometric design studies the analysts are faced with a problem of dealing with a large number of road sections that had no reported accidents during the observed period. For example, in a study by Zegeer et al. [1990], 55.7 percent of the road sections they studied had no reported vehicle accidents in a 5-year period, and in another study by Miaou and Lum [1993], over 80 percent of the road sections had no reported truck accidents during a 1-year period. This suggests that for a period of several years most of the road sections considered would have a high probability of being observed with no accidents. In other words, the underlying distribution of the occurrences of vehicle accidents on most of the road sections during the observed period is positively or rightly skewed. The conventional multiple linear regression models, which must rely on normal assumption, have been demonstrated to be lack of distributional property to describe adequately the random and discrete vehicle accident events on the road [Jovanis and Chang, 1986; Saccomanno and Buyco, 1988; Miaou and Lum, in press]. As a result, these linear regression models are not appropriate to make probabilistic statements about vehicle accidents on the road, and test statistics derived from these models are questionable.

The unsatisfactory property of linear regression models has led to the investigation of the Poisson and negative binomial (NB) regression models in recent studies [Maycock and Hall, 1984; Joshua and Garber, 1990; Miaou et al., 1991; Miaou et al., 1992; Miaou et al., in press; Miaou and Lum, 1993]. Although the Poisson and NB regression models have been found to have desirable distributional property to describe the vehicle accidents-geometric design relationship, these models are not without limitations. In addition, the relative performance of these models in establishing such relationships has not been fully evaluated.

The objective of this paper is to evaluate the statistical performance of the Poisson and NB 
regression models in establishing the relationship between truck accidents and geometric design of road sections. Three types of models are considered: Poisson regression, zero-inflated Poisson (ZIP) $\mathrm{rf}_{2}$ ession, and NB regression. Maximum likelihood (MI) method is used to estimate the unknown parameters of these models. Two other feasible estimators for estimating the dispersion parameter in the NB regression model are also examined: a moment estimator and a regression-based estimator. These models and estimators are evaluated based on their (1) estimated regression parameters and associated t-statistics, (2) overall goodness-of-fit, (3) estimated relative frequency of truck accident involvements across road sections, (4) sensitivity to the inclusion of short road sections, and (5) estimated total number of truck accident involvements. Data from the Highway Safety Information System (HSIS), a highway safety data base administered by the Federal Highway Administration (FHWA), are employed to examine the performance of these models in developing such relationships.

The remaining paper is organized as follows. First, three types of Poisson and NB regression models used for studying truck accidents and geometric design relationships are presented. Second, the performance of these models are evaluated using the HSIS data. The last section concludes the study.

\section{MODEIS AND ESTIMATORS}

Consider a set of $n$ road sections of a particular roadway type, say, rural Interstate. Let $Y_{i}$ be a random variable representing the number of trucks involved in accidents on road section $i$ during a period of one year, where $i=1,2, \ldots, n$. Note that the same road section in different sample periods are considered as separate road sections; this allows the year-to-year changes in geometric design, traffic conditions, and other relevant attributes to be considered in the model. Further, let the actual observation of $Y_{i}$ during the period be denoted as $y_{i}$, where $y_{i}=0,1,2,3, \ldots$ and $i=1,2, \ldots, n$. Also, let the amount of truck travel (or truck exposire) during the sample year on this road section be $v_{i}$ and computed as $365 \times \mathrm{AADT}_{i} \times \mathrm{T}_{i} \times \ell_{i}$, where $\mathrm{AADT}_{\mathrm{i}}$ is the average annual daily traffic (in number of vehicles), $\mathrm{T} \%_{i}$ is the percentage of trucks in the traffic stream, and $\mathrm{f}_{i}$ is the length of road section

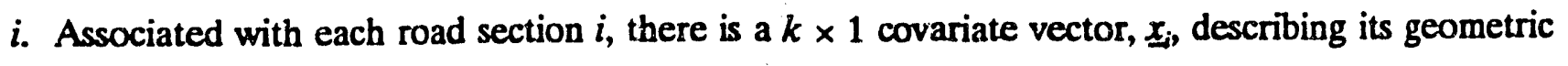
characteristics, traffic conditions, and other relevant attributes. The transpose of the covariate vector is denoted by $x_{i}^{\prime}=\left(x_{i 1}, x_{i z}, \ldots, x_{i k}\right)$. Without loss of generality, let the first covariate $x_{i l}$ be a dummy variable equal to one for all $i$ (i.e., $x_{i 1}=1$ ). Some of the covariates can be 0,1 dummy variables, indicating the presence or absence of a condition.

The general forms of these three types of regression models and brief descriptions of their estimation procedures are presented in this section. All models are formulated under the assumption that (1) the occurrences of truck accidents on different road sections are independent, and (2) truck miles data and other covariates are free from errors. 


\section{Poisson Regression Model}

The Poisson regression model considered in this study is the one used by Miaou et al. [1991]:

$$
p\left(Y_{i}=y_{1}\right)=p\left(y_{1}\right)=\frac{\mu_{i}^{y_{1}} e^{-\mu_{1}}}{y_{l} !} \quad i=1,2,3, \ldots, n .
$$

where

$$
\mu_{l}=E\left(Y_{i}\right)=v_{l}\left[e^{x_{i}}\right]=v_{l}\left[e^{\sum_{i-1}^{k} x_{i} \beta_{l}}\right] \quad i=1,2,3, \ldots, n .
$$

where $\beta$ is a $k \times 1$ vector of unknown regression parameters, the transpose of which is denoted by $\mathbf{2}^{\prime}=\left(\beta_{1}, \beta_{2}, \ldots, \beta_{k}\right)$. This model assumes that $Y_{i}, i=1,2, \ldots, n$, are independently and Poisson distributed with mean $\mu_{i}$. The expected number of trucks involved in accidents $\mu_{i}$ or $E\left(Y_{i}\right)$ in this model is proportional to truck travel $v_{i}$. The model also assumes an exponential rate function, $\lambda_{i}=E\left(Y_{i}\right) / v_{i}=\exp \left(\underline{x}_{i}^{\prime} \hat{\beta}\right)$, which ensures that accident involvement rate is always nonnegative. This type of rate function has been widely employed in statistical literature and found to be very flexible in fitting different types of count data [e.g., Cox and Lewis, 1966; Cameron and Trivedi, 1986; Frome et al., 1990]. Note that whenever appropriate higher order and interaction terms of covariates can be included in Eq. (2) without difficulties.

The regression parameters $\beta$ of this model can be estimated using the ML method [Cramer, 1986], the quasi-likelihood method [McCullagh and Nelder, 1983], or the generalized least squares method [Carroll and Ruppert, 1989]. The estimated parameters from the last two methods would converge to those from the MI method as more iterations are used. For deriving the asymptotic variance and $t$-statistics of the estimated parameters using the second derivative of the loglikelihood function, see Cramer [1986] for reference.

A limitation of using the Poisson regression model, which is well-known in the statistical literature [e.g., Cox, 1983; Dean and Lawless, 1989], is that the variance of the data is restrained to be equal to the mean, $\operatorname{Var}\left(Y_{i}\right)=E\left(Y_{i}\right)\left(=\mu_{i}\right)$. In many applications, count data were found to display extra variation or overdispersion relative to a Poisson model [e.g., Dean and Lawless, 1989]. That is, the variance of the data was greater than what the Poisson model inticated. In vehicle accidentsgeometric design studies, the overdispersion could come from several possible sources, e.g., omitted variables, uncertainty in exposure data and covariates, and nonhomogeneous highway environment [Miaou et al., in press].

The consequences of ignoring the extra variations in the Poisson regression models are that consistent estimates, such as the ML estimates (MLE), of the regression parameters under the Poisson model, are still consistent; however, the variances of the estimated parameters would tend 
to be underestimated. in other words, when the sample size $n$ is large, the MLE $\hat{\text { under }}$ the Poisson regression model would still be close to the true parameter $B$, but we may overstate the significance levels of the estimated parameters [Cameron and Trivedi, 1990]. (Note that this is under the assumption that Eq. (2) is correctly specified.)

To correct for the overdispersion problem for the Poisson model, Wedderburn [1974] suggested that one could assume that the variance of $Y_{i}$ is $\tau \mu_{\mathrm{i}}$ instead of $\mu_{\mathrm{i}}$, where $\tau$ is referred to as overdispersion parameter (and $\tau \geq 1$ ). It was also suggested that the overdispersion parameter $\tau$ corriu be estimated by $X^{2} /(n-k)$, where $X^{2}$ is the Pearson's chi-square statistic, $n$ is the number of obsurvations (i.e., the number of road sections), and $k$ is the number of unknown regression parameters in the Poisson model. The Pearson's $X^{2}$ statistic is computed as $\Sigma_{i}\left(y_{i}-\hat{\mathbb{R}}_{\mathrm{i}}\right)^{2} / \hat{\mathbb{R}}_{\mathrm{i}}$, where $\hat{\mathfrak{R}}_{\mathrm{i}}$ $=v_{i} \exp \left(\underline{x}_{i}^{\prime} \hat{\mathbf{B}}\right)$. A better estimate of the asymptotic $\mathrm{t}$-statistic for each regression parameter is $\tau^{-1 / 2}$ times that obtained from the original Poisson regression model based on the ML method [Agresti, 1990].

\section{Zero-Inflated Poisson Regression Model}

The particular ZIP regression model considered in this study has the following form:

$$
\begin{aligned}
& p\left(Y_{i}=y_{1}\right)=e^{-\theta_{1}} \quad \text { if } y_{i}=0 \\
& =\left(\frac{1-e^{-\theta r_{1}}}{1-e^{-r_{1}}}\right) \frac{r_{i} e^{-r_{1}}}{y_{i} !} \quad \text { if } y_{1}=1,2,3, \ldots
\end{aligned}
$$

and

$$
r_{1}=v_{i}\left[e^{x_{i}}\right]=v_{i}\left[e^{\sum_{j-1}^{k} x_{1}, \theta_{1}}\right] \quad i=1,2,3, \ldots, n
$$

where $0<\theta \leq 1$. (Note that for $\theta>1$, the probability of observing zeros is deflated rather than inflated.) Under this ZIP regression model, the mean and variance of $Y$, can be shown to be

$$
\mu_{1}=E\left(Y_{1}\right)=\left(\frac{1-e^{-\theta r_{1}}}{1-e^{-r_{1}}}\right) r_{i} \text { and } \operatorname{Var}\left(Y_{1}\right)=\mu_{i}+\left(\frac{1-e^{r_{1}(\theta-1)}}{e^{\theta r_{1}}-1}\right) \mu_{i}^{2}=\mu_{i}+\phi_{i} \mu_{i}^{2}
$$

where $\phi_{i}$ is a function of $r_{i}$ and $\theta$. When $\theta=1$, the ZIP regression model is identical to the Poisson regression model presented in Eqs. (1) and (2). Also, when $0<\theta<1$, one can show that the variance of $Y_{i}$ exceeds its mean. Thus, the ZIP regression model allows overdispersion in the data due to excess zeros when compared to the classic Poisson regression model.

One reason for considering the ZIP regression model is the potential underreporting of vehicle accidents, especially those minor injury and property damage accidents. If the number of 
trucks involved in accidents on road sections follow a Poissc distribution, then, because of underreporting, the "reported" number of trucks involved in accidents would follow a ZIP distribution under some underreporting conditions.

Although the ZIP regression is more flexible than the Pcisson regression, the interpretation of the ZIP regression can be difficult. For example, the expected number of trucks invoived in accidents $\mu_{i}$ is related to truck travel $v_{i}$ and other covariates $\underline{x}_{i}^{\prime}$ in a much more complicated way in the ZIP regression than that in the Poisson regression, and it is not as easy to see how an increase in $v_{i}$ or $\underline{x}_{i}^{\prime}$ would increase or decrease the mean $\mu_{i}$ in the ZIP regression. Noie, however, that the ZIP regression model still ensures that truck accident involvement rate is always nonnegative.

The MI estimation and other possible variations of the ZIP regression models have been discussed in Lambert [1992]. In this study, the ML method is used to estimate the unknown parameters $B$ and $\theta$, and their asymptotic standard deviations and t-statistics are estimated using the second derivative of the loglikelihood function (or the observed Fisher information matrix).

\section{Negative Binomial Regression Model}

To deal with the overdispersion problem in count data, one commonly used distribution is the NB distribution. The NB regression model considered in this study has the following form:

$$
p\left(Y_{i}=y_{i}\right)=\frac{\Gamma\left(y_{i}+\frac{1}{\alpha}\right)}{\Gamma\left(y_{i}+1\right) \Gamma\left(\frac{1}{\alpha}\right)}\left(\frac{1}{1+\alpha \mu_{i}}\right)^{\frac{1}{\alpha}}\left(\frac{\alpha \mu_{i}}{1+\alpha \mu_{i}}\right)^{y_{i}} \quad y_{i}=0,1,2, \ldots
$$

where

$$
\mu_{1}=E\left(Y_{1}\right)=v_{i}\left[e^{x_{1}}\right]=v_{i}\left[e^{\sum_{-1}^{k} x_{1}, \theta_{1}}\right] \quad i=1,2,3, \ldots, n
$$

and the variance of $Y_{i}$ is

$$
\operatorname{Var}\left(Y_{i}\right)=\mu_{1}+\alpha \mu_{i}^{2}
$$

where $\alpha \geq 0$ and is usually referred to as dispersion parameter. From Eq. (8) one can see that this model allows the variance to exceed the mean. Also, the Poisson regression model can be regarded as a limiting model of the negative binomial regression model as $\alpha$ approaches 0 .

The ML estimation of the NB regression model and the calculation of associated statistics are described in detail by Lawless [1987]. The moment estimation, which was first suggested by Breslow [1984], is also commonly used for estimating the parameters in the NB model. For comparison, in this study the moment estimation method as described in Lawless [1987] is also used for parameter 
estimation. The method is an iterative procedure until the estimated dispersion parameter converges.

Another estimation method considered in this study for estimating the NB regression model is a regression-based estimation method suggested by Cameron and Trivedi [1986, 1990]. The method is an iterative estimation procedure described below.

Step 1. Give an initial estimate of $\alpha$, say, $\hat{\alpha}_{1}$.

Step 2 Estimate $\underline{\beta}$ using the ML method, assuming $\alpha=\hat{\alpha}_{1}$. Let the estimate of $\underline{B}$ be $\hat{\underline{B}}$.

Step 3. Obtain the following regression estimator for $\alpha$ :

$$
\hat{\alpha}=\frac{\sum_{i=1}^{n} \hat{\mu}_{i}^{2}\left[\left(y_{i}-\hat{\mu}_{i}\right)^{2}-\hat{\mu}\right]}{\sum_{i=1}^{n} \hat{\mu}_{i}^{4}}
$$

where $\hat{\boldsymbol{P}}_{\mathbf{i}}=v_{i} \exp \left(\underline{x}_{i}^{\prime} \hat{\underline{B}}\right)$.

Step 4. If $\left|\hat{\alpha}-\hat{\alpha}_{1}\right|<\epsilon$, stop; else let $\hat{\alpha}_{1}=\hat{\alpha}$ and go to Step 2. Here, $\epsilon$ is a small positive number equal to, e.g., 0.001 .

The NB regression model using the ML method was used in Miaou et al. [in press] to establish truck accidents-geometric design relationships for three different roadway classes. Although the NB regression model is more general than the Poisson regression model, it requires more extensive computations to estimate model parameters and to generate inferential statistics than the Poisson regression model. Furthermore, the statistical property of different estimators, e.g., the MLE and moment estimators, of the NB regression model under different sample sizes have not yet heen fully investigated [Lawless, 1987].

Although the discussion above does not distinguish accidents by truck configuration and accident severity, in principal, these three types of Poisson and NB regression models could be applied to any truck type and accident severity type of interest, provided that there are enough accident data and that truck exposure by truck type can be properly estimated.

\section{MODEL EVALUATIONS}

\section{Data Source}

Data from the HSIS are employed to evaluate the performance of the Poisson and NB regression models (and estimators) described above in terms of its ability to establish truck accidents and geometric design relationships. Specifically, accidents involving large trucks on rural Interstate highways from Utah State are used. Note that here large trucks are defined as trucks with gross vehicle weight rating of $10,000 \mathrm{lb}$ or over. Among the five HSIS States available, Utah State was 
considered to be the State that had the most complete information on highway geometric design [Miaou et al., in press]. In addition, this particular State was the only HSIS State with a "historical" road inventory file in which year-to-year changes on highway geometric design and traffic conditions were recorded. Thus, accidents in a given year could be matched to the road inventory information of the same period. For this study, truck accident and road inventory data from 1985 to 1989 are used.

\section{Accidents, Characteristics of Road Sections, and Covariates}

Detailed descriptions of the data can be found in Miaou et al. [in press]. The time period considered in this study is one year, which means that the same road section, even if nothing had changed, is considered as five independent sections - one for each year from 1985 to 1989. As indicated earlier, this allows the year-to-year changes on highway geometric design and traffic conditions to be considered in the model. There is a total of 8,263 homogeneous road sections during the 5-year period. These road sections constitute 14,731 lane-miles of roadway, which covers over $98 \%$ of the total rural Interstate lane-miles in Utah during the period. Data for each year contain roughly onefifth of the total sections and lane-miles. The section lengths vary from 0.01 to $7.77 \mathrm{mi}(0.016$ to $12.43 \mathrm{~km})$ - with an average of $0.45 \mathrm{mi}(0.72 \mathrm{~km})$. Descriptive statistics of these 8,263 road sections on truck accident involvemeni and truck miles traveled are given in Table 1.

During the 5-year period, there were 1,643 large trucks reported to be involved in accidents on these highway sections, regardless of truck configuration and accident severity type. With the total truck miles estimated to be 2,030 million truck miles ( 3248 million truck kilometers), the overall truck accident involvement rate was 0.81 truck accident involvements per million truck miles $(0.51$ truck accident involvements per million truck kilometers). These accidents occurred on only 14 percent of the 8,263 road sections. The maximum number of trucks involved in accidents on an individual road section was 8 . On average, each section had 0.20 trucks involved in accidents in one year.

The covariates considered for individual road sections and their definitions are also presented in Table 1. They include (1) yearly dummy variables to capture year-to-year changes in the overall truck accident involvement rate due, e.g., to long-term trend, annual random fluctuations, changes in omitted variables such as weather; (2) AADT per lane, used as a surrogate measure for traffic density; (3) horizontal curvature; (4) vertical grade; and (5) deviation of paved inside (or left) shoulder width from an "ideal" width of $12 \mathrm{ft}$ per direction. Because all of the road sections are 12 $\mathrm{ft}$ in lane width, about 89 percent of them have 4 lanes, and all road sections have paved outside (or right) shoulder width of $10 \mathrm{ft}$ per direction, we are unable to test the effects of these variables.

It has been suggested that as length of grade increases to a point that can slow a truck to a 
speed significantly slower than the speed of the traffic stream (e.g., $10 \mathrm{mi} / \mathrm{h}$ or $16 \mathrm{~km} / \mathrm{h}$ ), the accident rate increases [Roy Jorgensen Associates, 1978]. Also, for a fixed curvature degree, as the length of curve increases, the accident rate increases [Zegeer et al, 1990]. In order to test the effects of length of curve and length of grade on truck accident involvement rate, two covariates - length of original curve and length of original grade - are considered. Because each curve or grade considered in the model may have been subdivided from a longer curve or grade for achieving total homogeneity, for each road section in the model these two covariates are defined as the length of the original undivided curve or grade to which this section belongs. In addition, these two covariates are defined only for curves with horizontal curvatures greater than 1 degree and sections with grade greater than 2 percent. (Note that these two covariates are set equal to 0 if horizontal curvature is less than or equal to 1 degree or if vertical grade is less than or equal to 2 percent.) This definition is based on an assumption that the length of a mild curve or grade has no aggravated effect on truck accident involvements. The interactions of horizontal curvature and length of original curve, vertical grade and length of original grade, and horizonal curvature and vertical grade are also considered.

Percent trucks in the traffic stream is included in the model to evaluate the effects of cartruck mix. Previous studies suggested that as percent trucks increases, truck accident involvement rate decreases. One possible reason is that, for a constant vehicle density, as percent trucks increases, the frequency of lane changing and overtaking movements by cars decreases. Also, previous records showed that more trucks involved in truck-car multivehicle accidents than in truck-truck accidents [Jovanis and Chang, 1986].

\section{Model Estimation Results}

The estimated parameters and associated t-statistics of five Poisson and NB regression models and estimators described in the previous section are presented in Table 2 . Discussion on variable selection and testing procedures can be found in Miaou and Lum [1993]. The Poisson and ZIP regression models are estimated using the ML method. The NB regression model is estimated using the ML method (NB-ML), moment method (NB-MOM), and regression-based method (NB-REG). The loglikelihood function evaluated at the estimated parameters, $L(\hat{B})$, and the Akaike Information Criterion (AIC) value [see, e.g., Bozdogan, 1987] for each model are also given in the table. Note that $\mathrm{AIC}=-2 \mathrm{~L}(\hat{B})+2 k$, where $k$ is the total number of unknown regression parameters in the model. Estimated models with high loglikelihood function and low AIC values are preferred. The Wedderburn's overdispersion parameter $\tau$ for the Poisson regression model is computed to adjust the estimated t-statistics from the MLE. Furthermore, the expected total number of trucks involved in accidents across road sections from the model $\left(\Sigma_{i} \hat{\boldsymbol{p}}_{\mathrm{i}}=\Sigma_{\mathrm{i}} \nu_{i} \exp \left(\underline{x}_{i}^{\prime} \hat{\underline{B}}\right)\right)$ is compared with the observed total $\left(\Sigma_{i} y_{i}\right)$. 
In order to examine the effect of short road sections on the estimation of different models and estimators, we remove road sections with section length less than or equal to $0.05 \mathrm{mi}(0.08 \mathrm{~km})$. As a result, a total of 1,259 road sections are eliminated. The remaining 7,004 road sections, which had 1,603 truck accident involvements, are used to develop new models. The results are also presented in Table 2.

To evaluate how well the Poisson regression, ZIP regression, and NB-ML models estimate the relative frequencies of truck accident involvements across road sections, the following comparison is made. First, the relative frequency of road sections with $k$ trucks involved in accidents is computed and denoted by $f_{k}$. More specifically, $f_{k}$ is the percentage of road sections which had $k$ truck accident involvements during the sampled year (i.e., $f_{k}=$ number of road sections with $k$ truck accident involvements/total number of road section $n$ ). Second, the estimated relative frequency is computed as: $\hat{f}_{k}=\Sigma_{i} \hat{p}\left(Y_{i}=k\right) / n$, where $\hat{p}\left(Y_{i}=k\right)$ is the estimated probability of having $k$ trucks involved in accidents, given the estimated parameters. The observed and estimated relative frequencies $\left(f_{k}\right.$ and $\left.\hat{f}_{k}\right)$ and their differences $\left(\hat{f}_{k}-f_{k}\right)$ are presented in Table 3 . In this table, the relative frequencies are computed for $k=0,1,2,3,4$ and for $k 25$. (Note that this kind of comparison has been used by Lambert [1992].)

\section{Model Performance}

From Tables 2 and 3, the following observations can be made:

1. Estimated regression parameters and associated t-statistics:

The comparison of the estimated parameters and t-statistics in Table 2 for the three models under the ML estimation method suggests not only that the conclusions reached regarding the significance level of the relationships between truck accidents and the examined traffic and geometric design variables are quite consistent, but also that most of the estimated regression parameter values are quite close. In addition, all of the estimated regression parameter values related to traffic and geometric design variables have the expected algebraic sign. Another observation is that the ZIP regression model seems to suggest slightly stronger relationships between truck accidents and horizontal curvature and between truck accidents and inside shoulder width than the other two models.

2. Sensitivity to the inclusion of short road sections:

Except the NB-MOM model, the estimated regression parameter values for each model only change slightly after the short road sections (with $q_{i}<0.05 \mathrm{mi}$ ) are removed from the data. Some of the estimated regression parameters of the NB-MOM model are somewhat different from those of the NB-ML model when short road sections are included in the model estimation. However, after removing the short road sections, the estimated regression 
parameter values from the two models become very close. This indicates that the NB regression model using the moment estimation is sensitive to the inclusion of short road sections. (Note that it has been shown by Miaou and Lum [in press] that those vehicle accidents-geometric design models based on conventional linear regressions are also very sensitive to the inclusion of short road sections.)

3. Overdispersion and dispersion parameters:

When all road sections are considered in the model, the Wedderburn's overdispersion parameter $\tau$ for the Poisson regression model is 1.57 . This suggests that the truck accident data used in this study are moderately overdispersed than what the Poisson models has implied. Also, when short road sections are excluded from the model, the Wedderburn's overdispersion parameter decreases to 1.32 , indicating that the overdispersion measure is somewhat inflated when short road sections are included in the model. For the NB regression model, the estimated dispersion parameter from the three estimators are quite different. The inclusion of short road sections does not affect the estimation from the ML and regression-based estimators, but tends to inflate the dispersion parameter when estimated using the moment method. Also, the regression estimator seems to have underestimated the dispersion parameter when compared to the ML estimator, Poisson regression model, and ZIP regression model.

4. AIC value, loglikelihood function, and relative frequency:

Based on the loglikelihood function and the AIC value, the NB-1vil model has better performance than the Poisson and ZIP regression models. However, by examining the estimated relative frequencies in Table 3 , it is found that no particular model is performing better than the other two models for all $k$ 's. For $k=0$, the NB-ML model performs the best and the ZIP model performs quite well; for $k=1,2,3$, the ZIP model performs the best; and for $k \geq 4$, the Poisson model performs the best. Therefore, it seems that the NB-ML model is performing better under the loglikelihood function and the AIC value simply because it provides better estimated probabilities of having no reported truck accident for different road sections and there are over $86 \%$ of the road sections that were reported to have no truck accident.

5. Expected versus observed total truck accident involvements:

Except the NB-MOM model, the expected total truck accident involvements are reasonably close to (or specifically within 4 percent of) the observed total when all road sections are considered in the model. After removing short road sections, the expected total from the NBMOM model is found to be closer to the observed total. This indicates that the estimated overall accident involvement rate is inflated in the NB-MOM model when short road sections 
are included. (Note that it was demonstrated in Miaou and Lum [in press] that conventional linear regression models can seriously overestimate or underestimate the total number of accident involvements across road sections.)

\section{Examples of Accident Probability}

To see how accident probability distribution varies under the taree regression models as the expected number of truck accident involvements increases, three by pothetical road sections are created to represent a low, a medium, and a high truck accident involve inent road section and are given in Table 4. The estimated accident probability distributions of ine three hypothetical road sections are given in Figure 1. When the expected number of truck accident involvements $\left(E\left(Y_{i}\right)\right)$ is low (say, $\left.<1\right)$, the estimated probability distributions $\left(\hat{p}\left(Y_{i}\right)\right)$ from the three models are quite similar in shape and magnitude. When $E\left(Y_{i}\right)$ is high (say, $\left.>2\right), \hat{p}\left(Y_{i}\right)$ from the three models deviate from one another subst: stially in shape and magnitude. Particularly, the NB-ML model suggests a much more diffused accident probability distribution than the other two models as $E\left(Y_{i}\right)$ increases beyond 2.

\section{CONCLUSIONS}

The performance of the Poisson and NB regression models in establishing the relationship between truck accidents and geometric design of road sections is evaluated using the HSIS data. The Poisson and ZIP regression models are estimated using the ML method, while the NB regression model are estimated using the ML, moment, and regression-based estimators. The NB model based on the moment method is quite sensitive to the inclusion of short road sections. While the NB model using the regression estimator tends to understate the dispersion of the data. Both estimators should be used with caution. Under the ML method, the estimated regression parameters from all three models are quite consistent and no particular model outperforms the other two models in terms of the estimated relative frequencies of truck accident involvements across road sections. The NB model performs the best in estimating the frequency of road sections with zero truck accident involvement. The ZIP model, on the other hand, performs the best in estimating the frequencies of road sections with 1,2 and 3 truck accident involvements. While the Poisson model performs the best in estimating the frequencies of road sections with 4 or more truck accident involvements. It is recommended that the Poisson regression model be used as an initial model for developing the relationship. If the overdispersion of accident data is found to be moderate or high (e.g., when the Wedderburn's overdispersion parameter $>1.3$ ), both the NB and ZIP regression models could be explored. Overall, the ZIP regression model appears to be a serious candidate model for studying the relationships when accident data exhibit excess zeros due, e.g., to underreporting. However, the interpretation of the ZIP model can be difficult. 


\section{ACKNOWLEDGEMENTS}

This paper is based on the results of a research project sponsored by the Office of Safety and Traffic Operations R\&D, Federal Highway Administration (FHWA), the U.S. Department of Transportation. The opinions expressed in this paper are, however, solely those of the author.

\section{REFERENCES}

1. Agresti, A., Categorical Data Anahysis, John Wiley, New York, 1990.

2. Breslow, N., "Extra-Poisson Variation in Log-Linear Models," Applied Statistics, 33, pp. 38-44, 1984.

3. Bozdogan, H., "Model Selection and Akaike's Information Criterion (AIC): The General Theory and Its Analytical Extensions," Psychometrika, 52(3), pp. 345-370, 1987.

4. Cameron, A.C., and Trivedi, P.K., "Econometric Models Based on Count Data: Comparisons and Applications of Some Estimators and Tests," Journal of Applied Econometrics, Vol. 1, pp. 29-53, 1986.

5. Cameron, A.C., and Trivedi, P.K., "Regression-Based Tests for Overdispersion in the Poisson Model," Joumal of Econometrics, Vol. 46, pp. 347-364, 1990.

6. Carroll, R.J., and Ruppert, D., Transformation and Weighting in Regression, Chapman and Hall, New York, 1988.

7. Cox, D.R., "Some Remarks on Overdispersion," Biometrika, 70(1), pp. 269-274, 1983.

8. Cox, D.R., and Lewis, P.A.W., The Statistical Analysis of Series of Events, Chapman and Hall, London, 1966.

9. Cramer, J.S., Econometric Applications of Maximum Likelihood Methods, Cambridge University Press, New York, 1986.

10. Dean, C., and Lawless, J.F., Tests for Detecting Overdispersion in Poisson Regression Models," Joumal of the American Statistical Association, Vol. 84, No. 406, pp. 467-472, June 1989.

11. Frome, EL, Cragle, D.L., and McLain, R.W., "Poisson Regression Analysis of the Mortality among a Cohort of World War II Nuclear Industry Workers," Radiation Research, Vol. 123, pp. 138-152, 1990.

12. Lambert, D., "Zero-Inflated Poisson Regression, With an Application to Defects in Manufacturing," Technometrics, Vol. 34, No. 1, February 1992

13. Joshua, S.C., and Garber, N.J., "Estimating Truck Accident Rate and Involvements Using Linear and Poisson Regression Models," Transportation Planning and Technology, Vol. 15, pp. 41-58, 1990.

14. Jovanis, P.P., and Chang, H.L, "Modeling the Relationship of Accidents to Miles Traveled," Transportation Research Record 1068, Transportation Research Board, National Research Council, Washington, D.C., pp. 42-51, 1986.

15. Lawless, J.F., "Negative Binomial and Mixed Poisson Regression," The Canadian Joumal of Statistics, Vol. 15, No. 3, pp. 209-225, 1987. 
16. Maycock, G., and Hall, R.D., Accidents at 4-Arm Roundabouts, Transport and Road Research Laboratory Report 1120, 1984.

17. McCullagh, P., and Nelder, J.A., Generalized Linear Models, Chapman and Hall, London, 1983.

18. Miaou, S.-P., Hu, P.S., Wright, T., Davis, S.C., and Rathi, A.K., Development of Relationships between Truck Accidents and Highway Geometric Design: Phase I, Technical Memorandum prepared by the Oak Ridge National Laboratory for the Federal Highway Administration, March and November 1991.

19. Miaou, S.-P., Hu, P.S., Wright, T., Rathi, A.K, and Davis, S.C., "Relationships between Truck Accidents and Highway Geometric Design: A Poisson Regression Approach," Transportation Research Record 1376, pp. 10-18, 1992.

20. Miaou, S.-P., and Lum, H., "Modeling Vehicle Accidents and Highway Geometric Design Relationships," Accident Analysis \& Prevention, in press.

21. Miaou, S.-P., and Lum, H., "A Statistical Evaluation of the Effects of Highway Geometric Design on Truck Accident Involvements," Transportation Research Record, in press, 1993.

22. Miaou, S.-P., Hu, P.S., Wright, T., Davis, S.C., and Rathi, A.K, Development of Relationships between Truck Accidents and Geometric Design: Phase I, FHWA-RD-91-124, Federal Highway Administration, in press.

23. Okamoto, H., and Koshi, M., "A method to Cope with the Random Errors of Observed Accident Rates in Regression Analysis," Accident Analysis \& Prevention, Vol. 21, No. 4, pp. 317-332, 1989.

24. Roy Jorgensen Associates, Inc., Cost and Safety Effectiveness of Highway Design Elements, prepared for the National Cooperative Highway Research Program, Report 197, Washington, D.C., 1978.

25. Saccomanno, F.F., and Buyco, C., "Generalized Loglinear Models of Truck Accident Rates," paper presented at Transportation Research Board 67th Annual Meeting, Washington, D.C., January 1988.

26. Wedderburn, R.W.M., "Quasi-Likelihood Functions, Generalized Linear Models, and the Gauss-Newton Method," Biometrika, 54, pp. 439-447, 1974.

27. Zegeer, C.V., Hummer, J., Reinfurt, D., Herf, L, and Hunter, W., Safety Effects of CrossSection Design for Two-Lane Road, Volumes I and II, prepared for the Federial Highway Administration and Transportation Research Board by the University of North Carolina, October 1987.

28. Zegeer, C.V., Stewart, R., Reinfurt, D., Council, F., Neuman, T., Hamilton, E, Miller, T., and Hunter, W., Cost Effective Geometric Improvements for Safety Upgrading of Horizontal Curves, prepared for the Federal Highway Administration by the University of North Carolina, May 1990. 


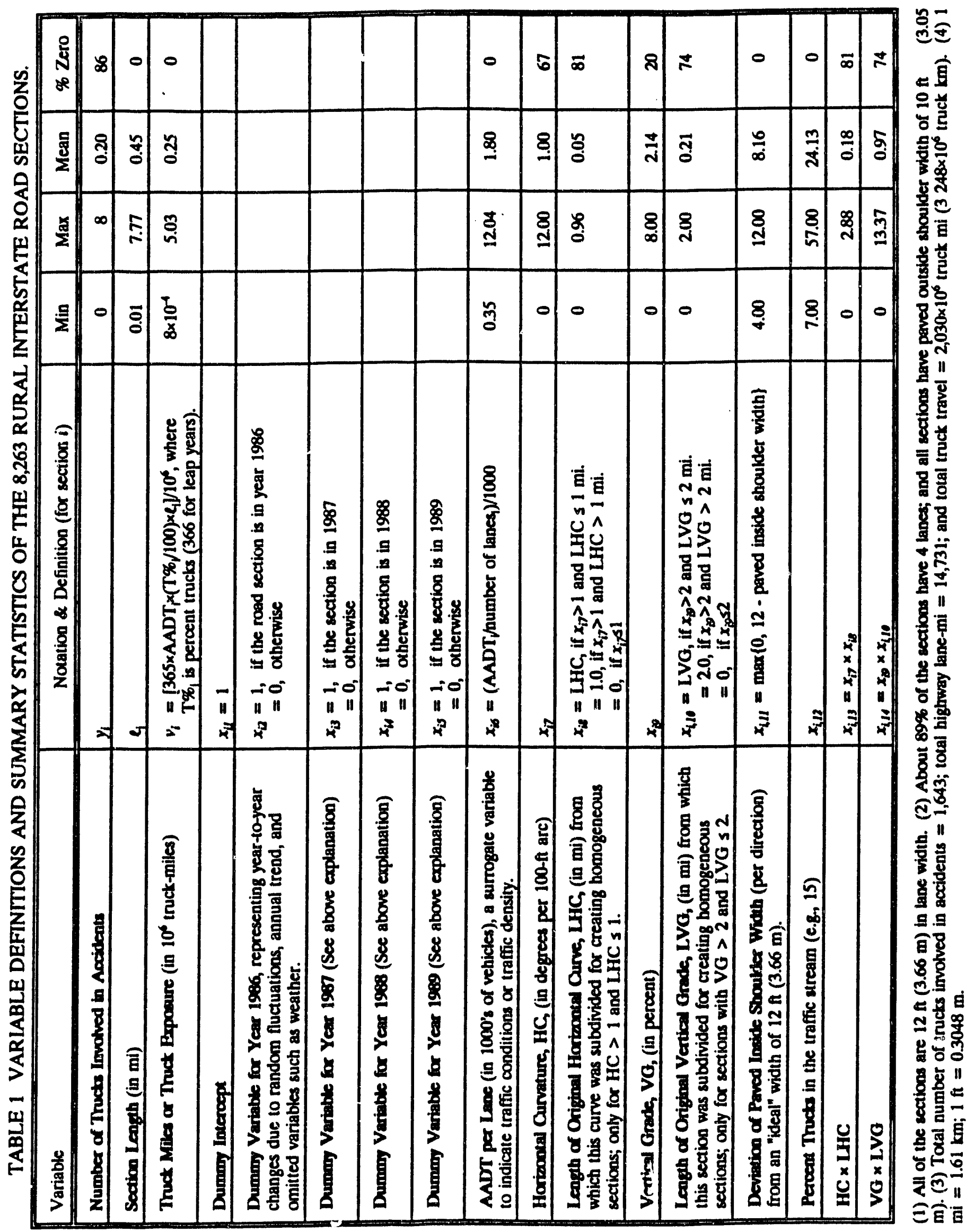




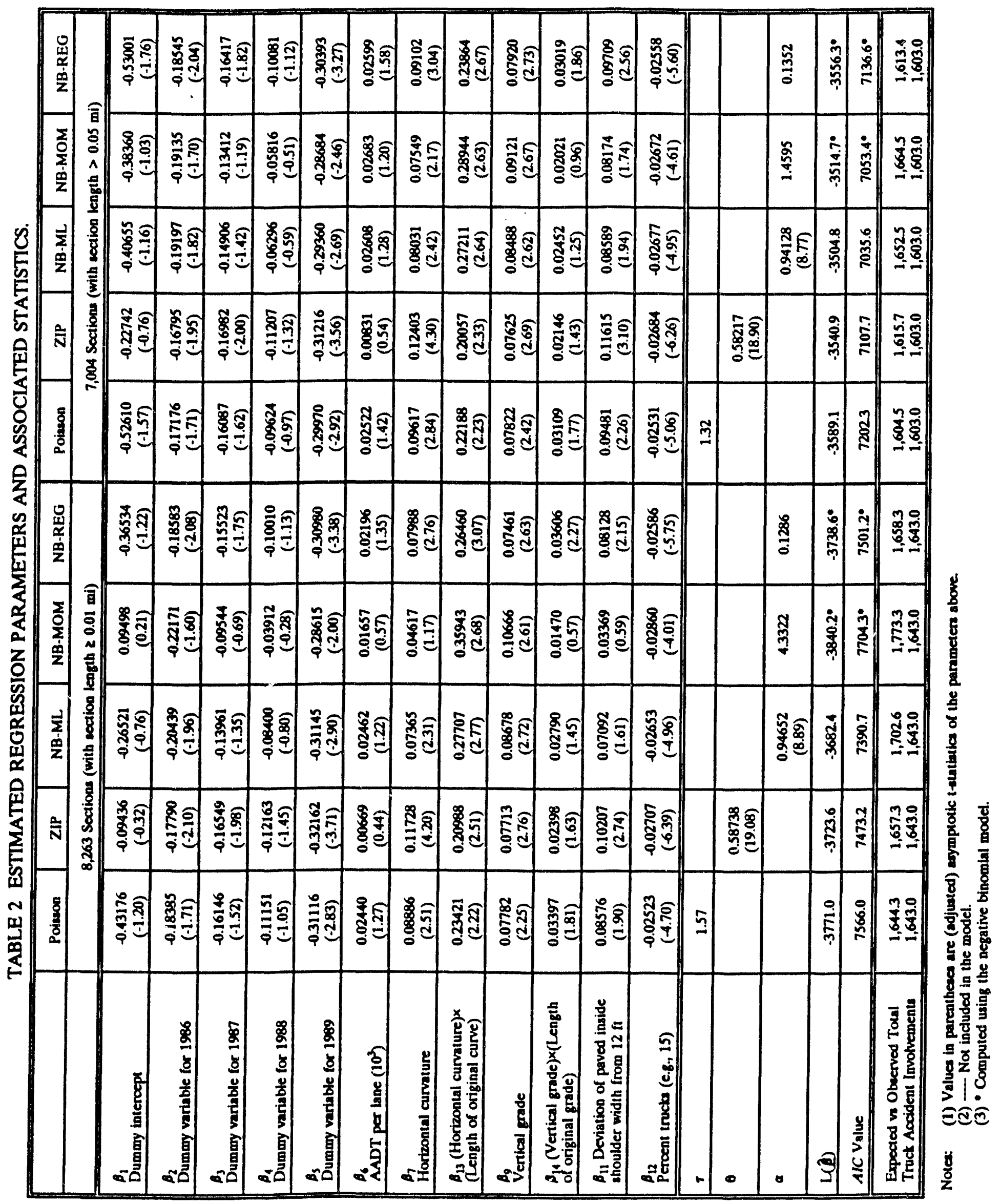




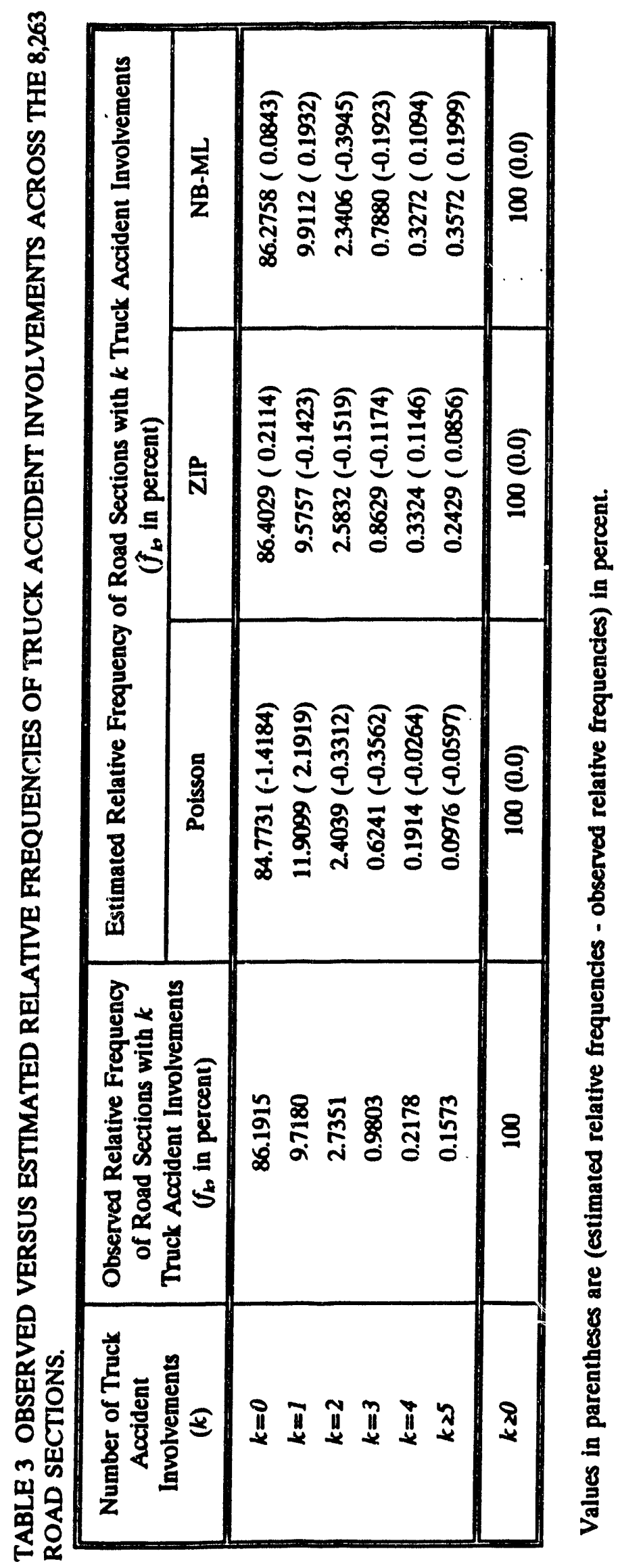


TABLE 4 TRUCK ACCIDENT INVOLVEMENT RATES AND ACCIDENT PROBABIIITIES OF THREE EXAMPLE ROAD SECTIONS.

\begin{tabular}{|c|c|c|c|c|}
\hline Variables & Model & Section \#1 & Section \#2 & Section \#3 \\
\hline Year & & 1989 & 1989 & 1989 \\
\hline Lane Width ( $t$ ) & & 12 & 12 & 12 \\
\hline Number of Lanes & & 4 & 4 & 4 \\
\hline Section Length (mi) & & 0.3 & 0.3 & 0.3 \\
\hline AADT (number of vehicles) & & 5,000 & 25,000 & 50,000 \\
\hline Horizontal Curvature (degree/100 it arc) & & $\mathbf{0}$ & 3 & 6 \\
\hline Length of Original Curve (mi) & & $\mathbf{0}$ & 0.5 & 0.5 \\
\hline Vertical Grade (percent) & & $\mathbf{0}$ & 3 & 3 \\
\hline Length of Original Grade (mi) & & $\mathbf{0}$ & 0.3 & 0.3 \\
\hline Pared Inside Shoulder Width (ft) & & 10 & 6 & 6 \\
\hline Paved Outside Shoulder Width (ft) & & 10 & 10 & 10 \\
\hline Percent Trucks & & 25 & 25 & 25 \\
\hline Truct Accident Involvement Rate $\left(\lambda_{i}\right)$ & $\begin{array}{l}\text { Poisson } \\
\text { ZIP } \\
\text { NB-MI }\end{array}$ & $\begin{array}{l}0.3089 \\
0.2464 \\
0.3439\end{array}$ & $\begin{array}{l}1.1881 \\
1.1554 \\
1.2989\end{array}$ & $\begin{array}{l}25669 \\
3.0861 \\
28631\end{array}$ \\
\hline $\begin{array}{l}\text { Expected Number of Truck Accident } \\
\text { Involvements }\left(E\left(Y_{i}\right)=\mu_{i}\right)\end{array}$ & $\begin{array}{l}\text { Poisson } \\
\text { ZIP } \\
\text { NB-MIL }\end{array}$ & $\begin{array}{l}0.0423 \\
0.0337 \\
0.0471\end{array}$ & $\begin{array}{l}0.8131 \\
0.7908 \\
0.8889\end{array}$ & $\begin{array}{l}3.5135 \\
4.2241 \\
3.9189\end{array}$ \\
\hline $\begin{array}{l}\text { Variance of Truct Accident } \\
\text { Involvements }\left(\operatorname{Var}\left(Y_{i}\right)\right)\end{array}$ & $\begin{array}{l}\text { Poisson } \\
\text { ZIP } \\
\text { NB-ML }\end{array}$ & $\begin{array}{l}0.0423 \\
0.0345 \\
0.0492\end{array}$ & $\begin{array}{l}0.8131 \\
1.0410 \\
1.6368\end{array}$ & $\begin{array}{r}3.5135 \\
5.3787 \\
18.4556\end{array}$ \\
\hline $\begin{array}{l}\text { Probability of Truct Accident } \\
\text { Involvements }\left(p\left(Y_{i}\right)\right)\end{array}$ & & Fig. 1(a) & Fig. 1(b) & Fig. 1(c) \\
\hline
\end{tabular}

$1 \mathrm{mi}=1.61 \mathrm{~km} ; 1 \mathrm{ft}=0.3048 \mathrm{~m}$. 


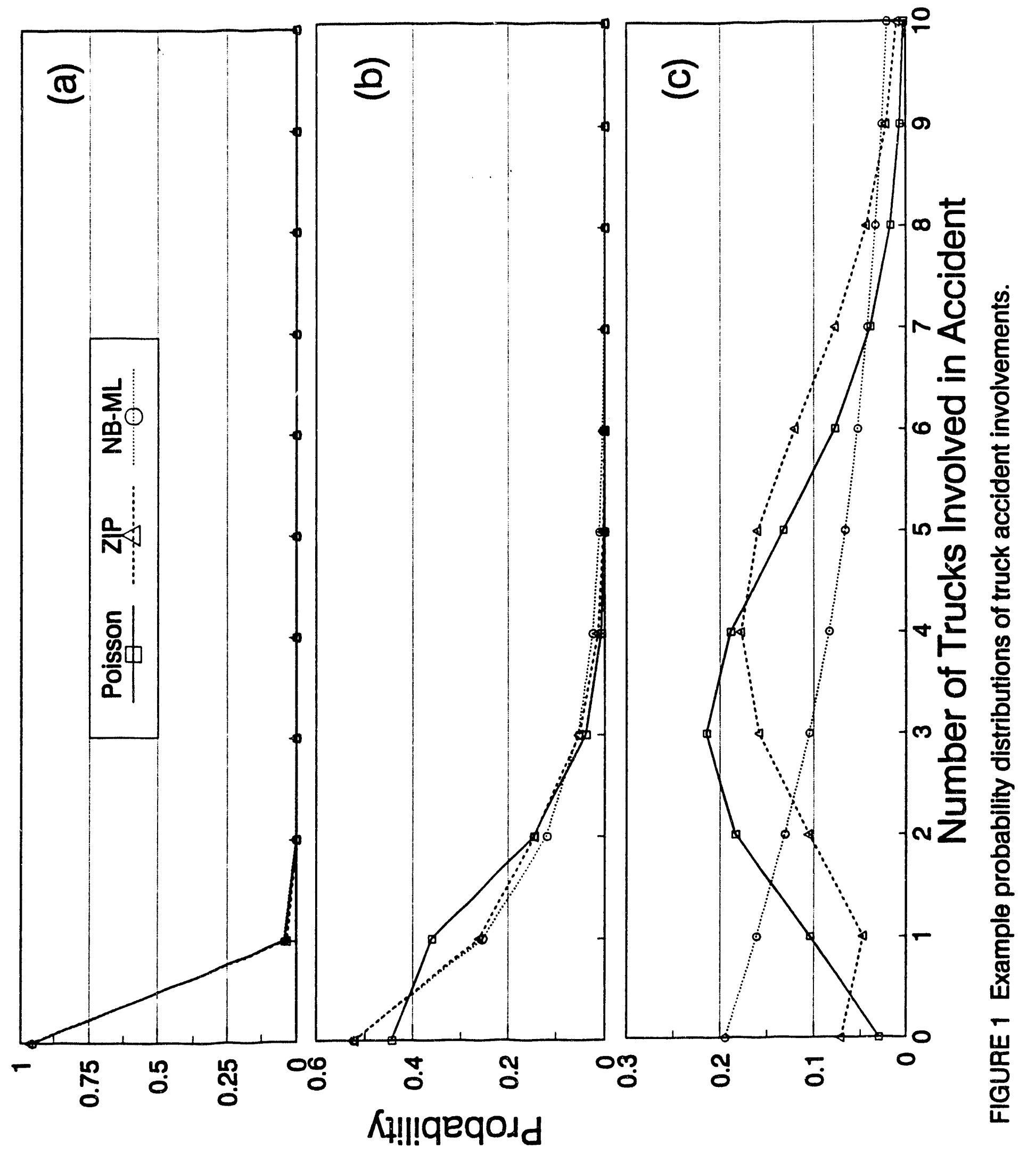



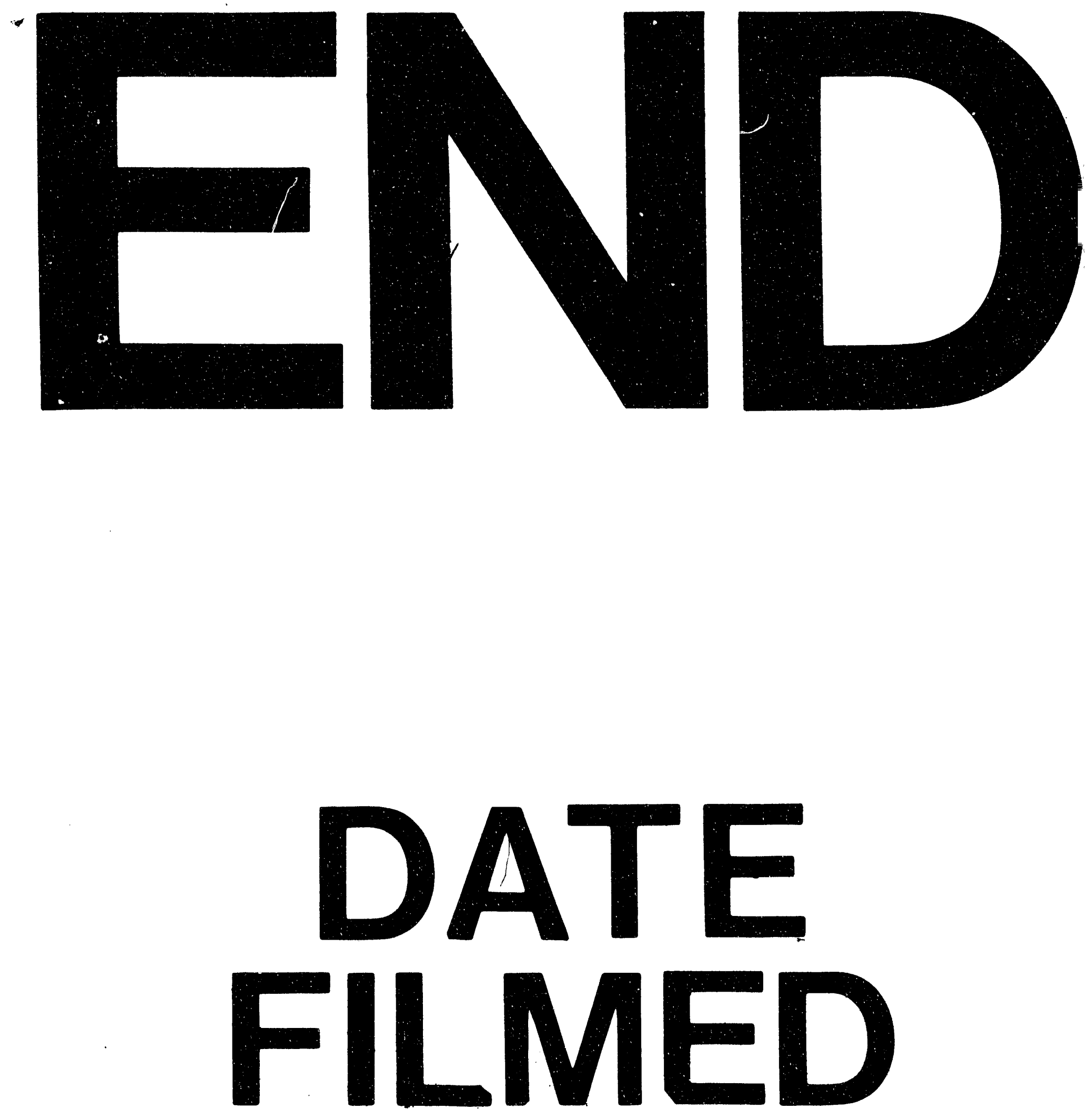

I

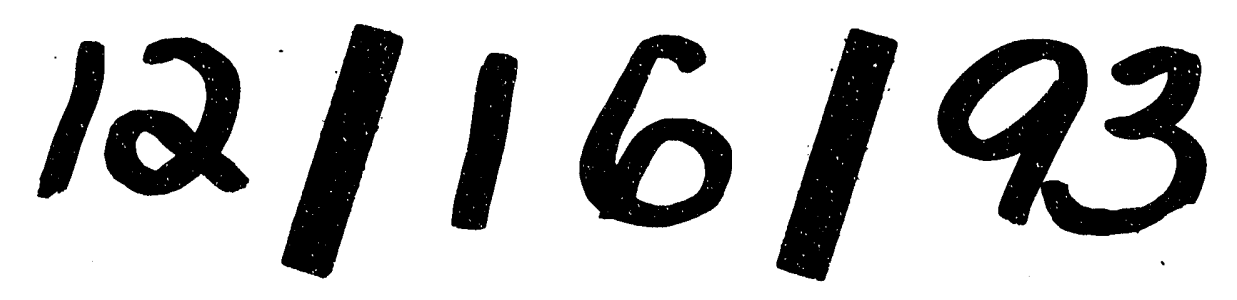


